\title{
Study on Pre Pumping and Outburst Elimination Technology of "one hole and two elimination" in Bedding Directional Long Drilling
}

\author{
Benqing Yuan ${ }^{1,2,3, *}$ Yongjiang Zhang ${ }^{1,3}$ \\ ${ }^{1}$ Chongqing Research Institute CO., Ltd of China Coal Technology Engineering Group, Chongqing, China \\ ${ }^{2}$ Anhui University of Science and Technology, Huainan 232001, China \\ ${ }^{3}$ National Key Laboratory of Gas Disaster Monitoring and Emergency Technology, Chongqing, China
}

\begin{abstract}
Aiming at the problem of gas control in the working face and the roadway to be excavated at the same time due to the small construction length of bedding borehole under the condition of the occurrence of soft coal, a technology of "one hole and two elimination" pre-drainage to eliminate gas outburst by using air screw motor drilling was put forward, and the field test was carried out in the 17102(3) working face of Pansu Coal Mine.The results show that this technology can effectively control the borehole trajectory, ensure the uniform and reasonable range of borehole outburst elimination, solve the problems of long gas treatment cycle caused by the construction of gas treatment roadway, improve the effective drainage time of borehole, ensure enough time and space for gas treatment, and be beneficial to the mining and replacement of mine.
\end{abstract}

\section{1 "One hole two elimination" technology principle}

"One hole two elimination " technique is to use the roadway drivage face side has the construction site, the rig directional construction some bedding boring (generally more than $200 \mathrm{~m}$ ), bedding near borehole control with mining face mining areas and with digging coal roadway stripe area (Fig.1), then use bedding directional borehole extraction control area of coal seam gas drilling,In order to solve the problem of small control range of short drilling, many drilling holes, long moving time during construction, short extraction time, uncontrollable deviation of drilling holes resulting in drilling holes can not be uniformly distributed in the coal seam according to the design, and relieve the tension of extraction and mining replacement $[1-3]$.

\section{Engineering geological condition}

The 17102(3) working face of Pan-San Mine is located in Dong-si Mining Area with elevation of -680 -724m. The mining strike length of the working face is $1820 \mathrm{~m}$ (including $1048 \mathrm{~m}$ solid section), the dip width is $200 \mathrm{~m}$, the $13-1$ coal thickness is $3.2 \sim 4.7 \mathrm{~m}$, the average thickness is $4.0 \mathrm{~m}$, the average dip Angle is $8^{\circ}$, and the measured gas pressure is $2.8 \mathrm{MPa}$. The gas content is $8.4 \mathrm{~m}^{3} / \mathrm{t}$, and the permeability coefficient of coal seam is $0.022 \mathrm{~m}^{2} /\left(\mathrm{MPa}^{2} \cdot \mathrm{d}\right)$.

\footnotetext{
*orresponding author: 2012156@cqceteg.com
}

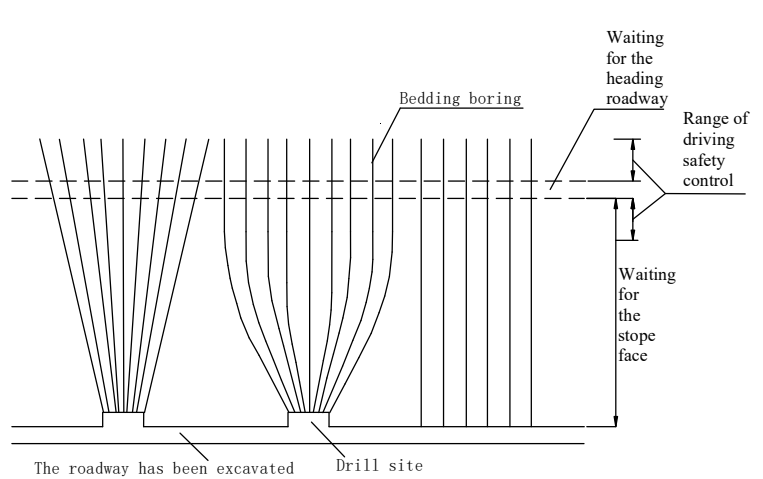

(a) Plan

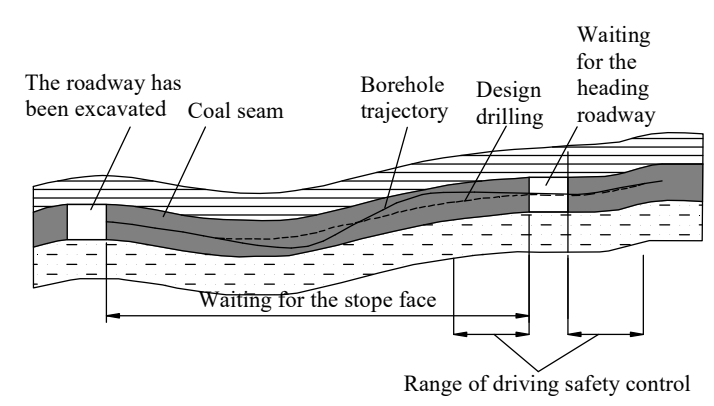

(b) Profile map

Fig. 1 Schematic diagram of "one hole and two elimination" drilling layout

17102(3) track grooves are goaf tunneling roadways. In order to solve the problem of gas outburst on the coal working face and transportation grooves at the same time after tunneling is completed, 17102(3) track grooves are considered as the drilling site to drill long boreholes into 
the coal working face and transportation grooves for regional pre-drainage and outburst elimination, that is, "one hole and two elimination".(3) The design length of the transport route is $1,820 \mathrm{~m}$, of which $1,048 \mathrm{~m}$ in the western section is located in the solid section of the outburst danger zone. In the solid section, $100 \mathrm{~m}$ area is selected as the "one hole and two elimination" test area.However, directional drilling of bedding borehole is difficult, the borehole trajectory is difficult to effectively control, and the gas treatment period is long caused by the construction of gas treatment roadway, etc., which are difficult problems for the implementation of "one hole and two elimination" technology.

\section{Drilling equipment technology}

\subsection{Drilling equipment}

\subsubsection{Rig equipment}

ZDY6000LD (F) type crawler full hydraulic tunnel drill produced by $\mathrm{Xi}$ 'an Coal Research Institute is selected as the construction rig, as shown in Fig 2.

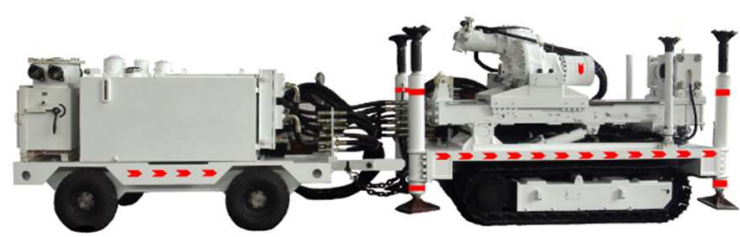

Fig.2 ZDY6000LD (F) model crawler type hydraulic tunnel drill for coal mine

\subsubsection{Drilling assembly}

1) Drilling BHA

$\Phi 108 \mathrm{~mm}$ drill bit $+73 / 83 \mathrm{~mm}$ outer screw pneumatic motor $+81 \mathrm{~mm}$ outer screw non-magnetic drill pipe + $81 \mathrm{~mm}$ outer screw probe pipe + insulation sub $+81 \mathrm{~mm}$ non-magnetic drill pipe + top $73 \mathrm{~mm}$ auger pipe, as shown in Fig. 3.

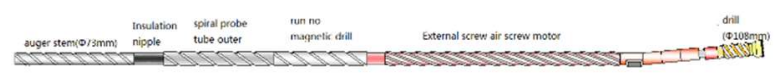

Fig.3 Drilling BHA

2) Run a casing assembly

$\Phi 92 \mathrm{~mm}$ steerable bit $+73-40 \mathrm{~mm}$ integrated large hole auger. The $92 \mathrm{~mm}$ steerable bit is shown in Fig. 4.

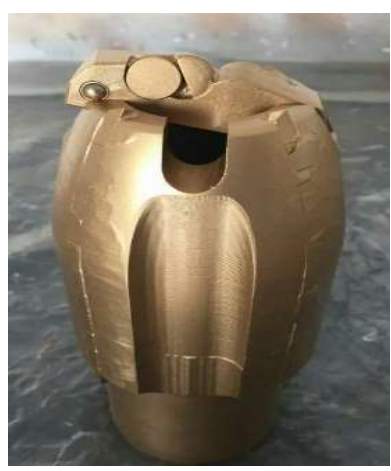

Fig.4 $\Phi 92 \mathrm{~mm}$ guided open and close drill bit

\subsubsection{Air screw motor}

Air screw motor surface smooth type outside diameter $73 \mathrm{~mm}$, spiral type outside diameter $85 \mathrm{~mm}$, length 4 $4.4 \mathrm{~m}$, front deflection $1.25 \sim 1.5^{\circ}$, as shown in Fig.5.

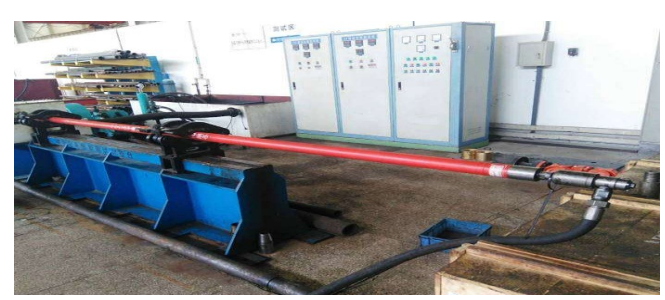

Fig.5 Air screw motor (flat)

\subsubsection{Wireless measuring system}

Wireless measurement system transmission distance is not less than $500 \mathrm{~m}$, the transmission rate is as high as 50bps, the measurement time is about 40s, the measurement accuracy: Angle $\pm 0.2^{\circ}$, azimuth Angle $\pm 1.2^{\circ}$, tool facing Angle $\pm 1.2^{\circ}$. This is shown in Fig. 6 .

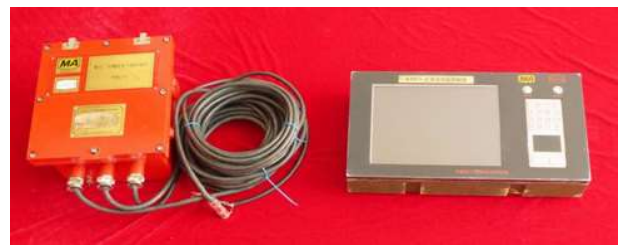

Fig.6 Wireless measuring system (outside hole part)

\subsubsection{Lubricating and cooling devices}

The hydraulic oil lubrication device improved by the foam generator lubricates and cools the motor to ensure the normal operation of the motor.The main structure includes storage tank, storage hydraulic oil, pressure gauge, communication pipeline, circulation pipeline, gate valve, flowmeter, flowmeter pipeline, structural support, etc., as shown in Fig. 7. 


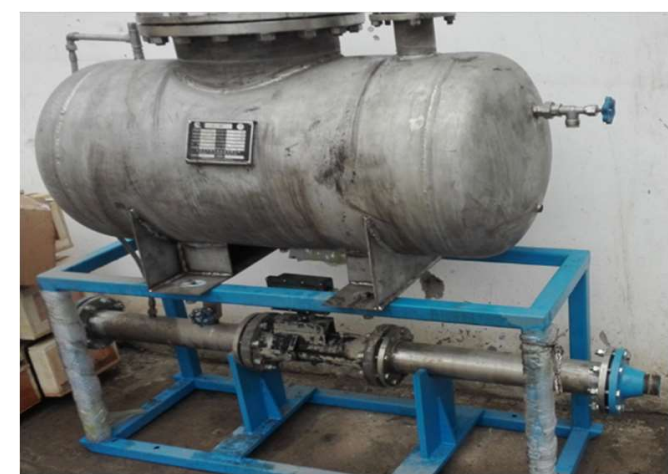

Fig.7 Lubricating device

\subsubsection{Air compressor}

The construction of bedding drilling adopts the process of pressing air and discharging slag, and the air pressure in the tunnel system is low. In order to ensure that the air pressure of drilling meets the requirements of drilling construction, the MLGF17/12.5-132G air compressor is selected, with an exhaust capacity of $17 \mathrm{~m}^{3} / \mathrm{min}$ and an exhaust pressure of $1.25 \mathrm{MPa}$.

\subsection{Technical parameters}

\subsubsection{Construction technology}

The construction technology of bedding directional drilling for soft coal seam is shown in Fig. 8. In view of the stress concentration area in the open hole section (generally $0 \sim 50 \mathrm{~m}$ ) of the construction area, the coal seam is extremely broken. Rotary drilling and grouting treatment are adopted in this section to ensure the stability of the open hole section ${ }^{[4]}$.For some coal seams are loose and broken, and collapse holes are easy to occur. The coal seams in local hole sections are wet, and it is difficult for directional drilling to discharge slag. Therefore, rotary composite drilling should be the main method to ensure normal drilling ${ }^{[5]}$.

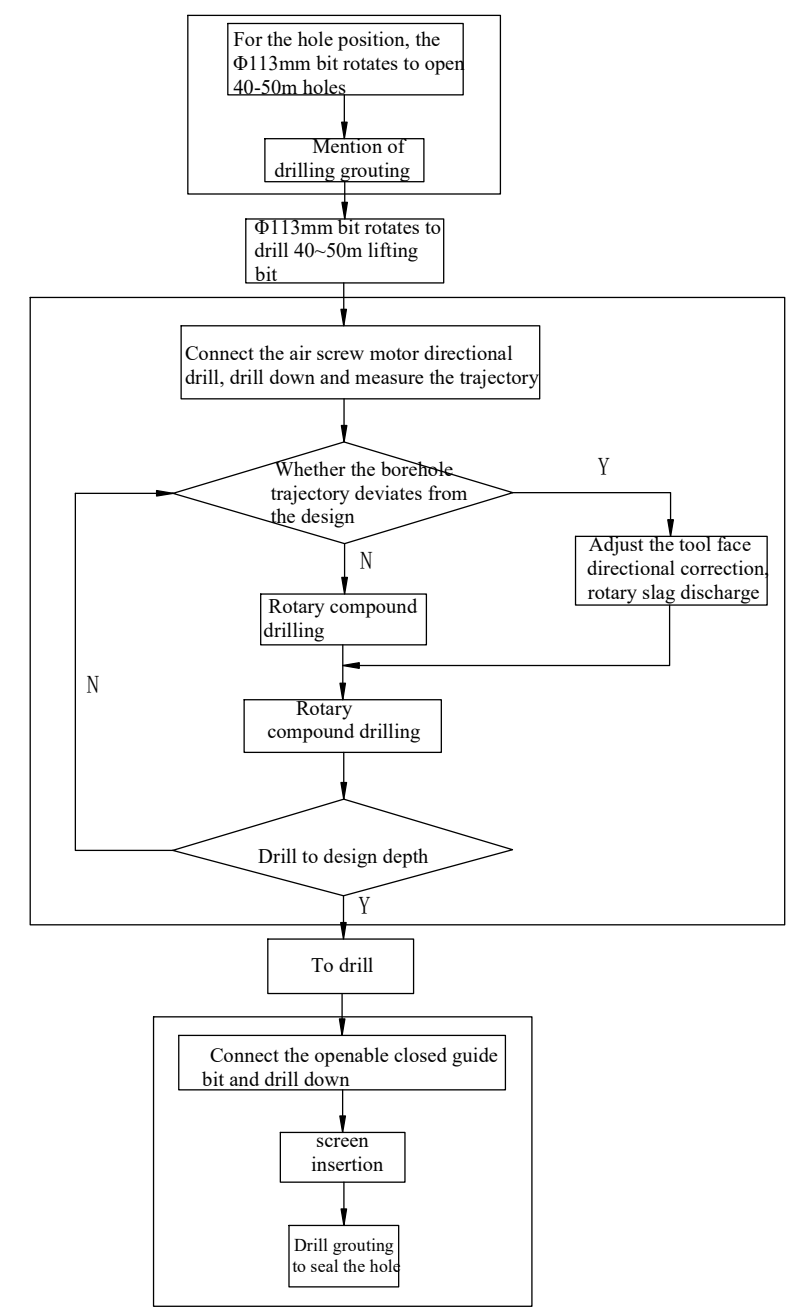

Fig.8 Construction process of directional long drilling along bedding

\subsubsection{Key parameter}

1) Drilling tools

$\Phi 108 \mathrm{~mm}$ drill bit $+73 / 83 \mathrm{~mm}$ external spiral pneumatic motor $+81 \mathrm{~mm}$ non-magnetic drill pipe under spiral + $81 \mathrm{~mm}$ external spiral probe pipe + insulation sub $+81 \mathrm{~mm}$ non-magnetic on spiral $+73 \mathrm{~mm}$ auger string.

2) Drilling parameters of air screw motor

Rotary drilling speed of 80 120r/min, air volume of more than $400 \mathrm{~m} 3 / \mathrm{h}$; The air volume of sliding directional drilling is more than $500 \mathrm{~m} 3 / \mathrm{h}$; When the air volume is lower than $400 \mathrm{~m} 3 / \mathrm{h}$, the rotary sweeper can fully discharge slag.

3) Directional drilling

The rotary composite drilling is the main method, and the sliding directional drilling is the auxiliary method. The directional drilling is $2 \sim 3 \mathrm{~m}$, and the rotary sweeping hole is used to drain the slag, and then the directional and rotary sweeping hole is continued to be repeated, so as to ensure the smooth inside the hole and the construction safety.

4) Finish the hole of screen tube

Adopt $\Phi 89 \mathrm{~mm}$ openable closed guide bit + A73mm integrated large hole auger drill, among which openable 
closed guide bit ensures the smooth running into the hole during the second trip and the reliable opening during the running of the screen.

After the completion of directional drilling, connect the openable closed guide bit and the large hole drill pipe to drill again. When the drilling reaches a predetermined depth, stop drilling and insert the hole protection screen pipe from the large hole drill pipe. When the screen pipe pushes the openable closed guide bit position at the bottom of the hole, open the head of the drill and the screen pipe can enter the hole through the drill bit.After the screen is in place, start pulling out the drill pipe, leaving the screen in the hole and the bit and drill pipe out of the hole.After the hole shielding screen tube is placed into the hole, $15 \sim 20 \mathrm{~m}$ outside the hole is covered with PVC pipe.

5) Drilling and sealing holes

The hole sealing process of "two plugging and one injection" was used to seal the hole. The hole sealing depth was $20 \mathrm{~m}$, polyurethane plug was used in the range of $5 \mathrm{~m}$ at the orifice and bottom of the hole, and grouting capsule was used for high pressure grouting at the middle $15 \mathrm{~m}$, with the grouting pressure not less than $2 \mathrm{MPa}$.

\section{4. "One hole two elimination" technical characteristics}

Existing single unprotected recoverable coal seams in or protective layer for the coal seams, occurrence condition of coal seam bedding directional drilling crossing with mining face and with digging a tunnel gas extraction of elimination technique, solve the end of the alley pumping + layer drilling or bedding combined gas control technology of drilling is large volume, high cost, long cycle, etc.It has the following characteristics ${ }^{[6]}$ :

(1) The directional drilling track across the working face can be oriented to ensure that the drilling hole is in the coal seam.Using the air screw motor directional drilling method can solve the problem that the roof or floor drilling is not in place because of the fluctuation of coal seam, which can easily be seen by the conventional rotary drilling, improve the drilling depth and coal seam drilling encounter rate of soft coal seam, realize the precise control of bedding drilling trajectory, and ensure the coverage of drilling to eliminate the blind area of gas extraction.

(2) The screen pipe under the whole hole section of directional drilling can guarantee the gas drainage channel, realize the gas pre-drainage and outburst elimination of the working face and roadway to be excavated, and ensure the safe excavation of the roadway and the safe mining of the coal working face.

(3) It can save the engineering quantity of floor roadway and through layer hole, and reduce the production cost while ensuring the safety of coal roadway excavation and working face mining.

\section{Application effect}

In order to solve the problem of gas outrush elimination in coal working face and transport roadway (return air roadway) at the same time, reduce the comprehensive cost input of supporting floor roadway and relieve the tension of mine production replacement, 17102 (3) working face with more complex gas and coal seam occurrence conditions was selected for field application of directional long drilling drainage technology along bed in Pansan Mine of Huainan mining area.

\subsection{Drilling construction}

17102 (3) A total of 19 directional long boreholes along the bedding were constructed in the return air roadway (Fig. 9). The completion parameters of the boreholes are shown in Table 1.According to the actual formation conditions of Pansan Mine, the directional long hole diameter of 17102 (3) working face is determined to be $\Phi 108 \mathrm{~mm}$. The boreholes are arranged in two rows, with opening heights of $1.2 \mathrm{~m}$ and $1.8 \mathrm{~m}$ respectively. The spacing of each row of holes is $0.6 \mathrm{~m}$, and the spacing of the final hole is $5 \mathrm{~m}$. The directional drilling construction technology is adopted to realize the drilling construction along the coal seam, improve the coal penetration rate of the long borehole along the bed, basically realize the control of the drilling trajectory, realize the precise directional construction, and the drilling penetration rate of 8 boreholes in the coal seam reaches $100 \%$.

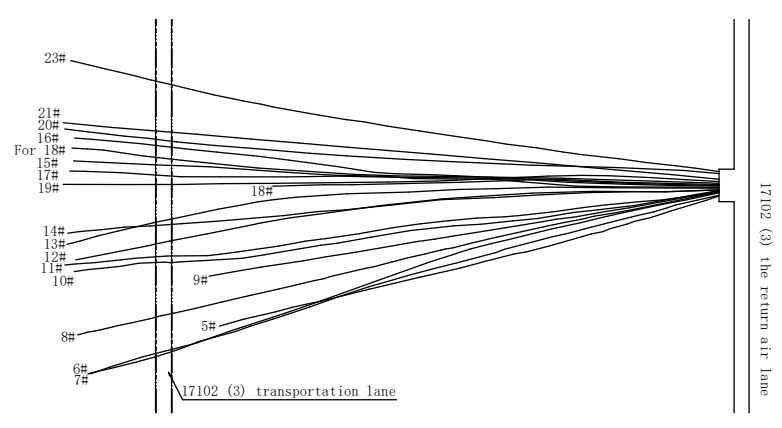

Fig. 9 Pore drawing of directional drilling construction in bedding

Table 117102 (3) Construction of directional drilling for bedding in return air roadway

\begin{tabular}{c|c|c|c|c|c|c|c}
\hline $\begin{array}{c}\text { Serial } \\
\text { number }\end{array}$ & $\begin{array}{c}\text { Boring } \\
\text { number }\end{array}$ & $\begin{array}{c}\text { Aperture } \\
/ \mathrm{mm}\end{array}$ & $\begin{array}{c}\text { Hole depth } \\
/ \mathrm{m}\end{array}$ & $\begin{array}{c}\text { Drill } \\
\text { encounter } \\
\text { rate/\% }\end{array}$ & $\begin{array}{c}\text { Sieve tube } \\
\text { length } \\
/ \mathrm{m}\end{array}$ & $\begin{array}{c}\text { Upper and } \\
\text { lower } \\
\text { deviation } \\
/ \mathrm{m}\end{array}$ & $\begin{array}{c}\text { Left-right } \\
\text { deviation } \\
/ \mathrm{m}\end{array}$ \\
\hline 1 & $23^{\#}$ & 108 & 231 & 85.54 & 231 & -0.87 & - \\
\hline 2 & $21^{\#}$ & 108 & 224.5 & 93.7 & 220 & -0.40 & -0.7 \\
\hline 3 & $20^{\#}$ & 108 & 225 & 93.7 & 214 & -1.03 & 1.9 \\
\hline 4 & $19^{\#}$ & 108 & 225 & 91.6 & 220 & -0.92 & -1.5 \\
\hline 5 & $18^{\#}$ & 108 & 160 & 100 & - & - & - \\
\hline 6 & For $18^{\#}$ & 108 & 221 & 100 & 220 & -1.88 & 1.4 \\
\hline 7 & $17^{\#}$ & 108 & 223 & 100 & 220 & -0.61 & -2.0 \\
\hline 8 & $16^{\#}$ & 108 & 221 & 89.6 & 220 & -1.94 & - \\
\hline 9 & $15^{\#}$ & 108 & 221 & 100 & 202 & -1.55 & \\
\hline 10 & $14^{\#}$ & 108 & 224.5 & 100 & 220 & -1.81 & -2.1 \\
\hline 11 & $13^{\#}$ & 108 & 222.5 & 100 & 220 & -1.4 & -1.4 \\
\hline 12 & $12^{\#}$ & 108 & 224 & 100 & 220 & -1.7 & -1.9 \\
\hline 13 & $11^{\#}$ & 108 & 224 & 91.5 & 220 & -2.0 & -0.9 \\
\hline 14 & $10^{\#}$ & 108 & 224 & 100 & 220 & -2.04 & 2.0 \\
\hline 15 & $8^{\#}$ & 108 & 224 & 100 & 218 & -1.9 & 1.1 \\
\hline 16 & $7^{\#}$ & 108 & 227 & 90.7 & 220 & -1.9 & -2.0 \\
\hline 17 & $6^{\#}$ & 108 & 227 & 93 & 220 & -1.72 & - \\
\hline 18 & $9^{\#}$ & 108 & 170 & 100 & 170 & - & - \\
\hline 19 & $5^{\#}$ & 108 & 175 & 100 & 171 & - & - \\
\hline
\end{tabular}




\subsection{Application effect}

Based on the failure characteristics of surrounding rock of deep mining roadway in huainan mining area, the grouting pressure of "two blocks and one injection" with pressure grouting and hole sealing method is calculated.According to the results of fluid mechanics and field grouting technology, the $P_{\mathrm{Z}}$ expression of grouting pressure is obtained as follows.

In order to test the drainage effect, six drill holes were constructed corresponding to 17102(3) transport lane. The maximum distance from the bedding directional drill was $6.4 \mathrm{~m}$, the measured maximum residual gas pressure was $0.35 \mathrm{MPa}$, and the residual gas content was $3.69 \mathrm{~m}^{3} / \mathrm{t}$.After inspection, the extraction within the control range of drilling is up to standard.

$17102(3)$ in the area where bedding directional drilling extraction technology is adopted in the transport roadway, the average driving footage is $9.3 \mathrm{~m} / \mathrm{d}$. Outburst risk cycle prediction is performed in the roadway driving process, and the maximum prediction indexes for outburst prevention are $S_{\max }=3.5 \mathrm{~kg} / \mathrm{m}$ and $\mathrm{Q}_{\max }$ $=2.91 \mathrm{~L} / \mathrm{min}$. During tunneling, the roadway air distribution volume was $960 \mathrm{~m}^{3} / \mathrm{min}$, and the maximum gas concentration of return air was $0.23 \%$, which realized safe and efficient tunneling.

\section{Conclusion}

(1) The technology innovation of "one hole and two elimination" of bedding long drilling is carried out. One bedding long drilling is carried out, and at the same time, the coal mining face and transportation groove are predrained and outburst is eliminated in the region, which saves a lot of engineering work of bedding through drilling.

(2) A good drainage effect was obtained. A total of $322,000 \mathrm{~m} 3$ of gas was extracted from 14 boreholes, the extraction rate was $61.3 \%$, the residual gas pressure was $0.35 \mathrm{MPa}$, and the residual gas content was $3.69 \mathrm{~m} 3 / \mathrm{t}$. The average gas concentration was still about $50 \%$ after 7 months, which was 3-4 times that of conventional drilling. (3) The directional drilling technology of "one hole and two elimination" bedding long borehole can effectively control the borehole trajectory, ensure the uniform and reasonable range of borehole outpouring elimination, and at the same time can fully discharge slag, ensure the unblocked drainage channel in the borehole, and improve the drainage effect.

(4) "One hole and two elimination" bedding long borehole is constructed in the groove by the track constructed in advance, which solves the problem of long gas treatment cycle caused by the construction of gas treatment roadway, improves the effective drainage time of borehole, ensures enough time and space for gas treatment, and is conducive to the production replacement of mine.

\section{Acknowledgments}

This work is financially supported by National Natural Science Foundation of China (No. 52004005), Anhui
Provincial Natural Science Foundation (No. 2008085QE222), China Postdoctoral Science Foundation (2021M691185), Anhui University of Science and Technology Introduction of Talents Research Fund Project, Scholastic Key Project (No. QN2019113), Patent Transformation and Cultivation Project (No. ZL201907).

\section{References}

1. Chen Jian, Luo Yong. Research on the technology of "one hole and two elimination" pre-drainage to eliminate outburst in bedding long borehole [J]. Mining Technology, 2020,20(5):47-50.

2. ZHANG Jie, WANG Yi, HUANG Hanjing, et al.Research on directional drilling technology of air srew motor in soft coal seam[J].Coal Science and Technology, 2018, 46(11):114-118.

3. WANG Xian, XU Chao, LIU Fei, JIANG Lei, et al. Key equipment and application effect analysis of ultra - long directional drilling along coal seam [J].Coal Engineering, 2019, 51(11):46-50.

4. WANG Yong, ZHOU Yan-an, TONG Xiao-zhang. Optimization and Application of Regional Antioutburst Measures in Pre-pumping Coal Seam Gas [J].Coal Technology, 2021, 40(02):133-136.

5. LI Yanqing,TANG Yongzhi, TANG Bin, et al. Innovation and development of coal and gas comining technology in Huainan mining area[J].Safety in Coal Mines, 2020, 51(8):77-81.

6. FANG Jun, LI Quanxin, XU Chao, et al.Construction technology and development tendency of gas drainage borehole in soft and outburst seam[J]. Coal Science and Technology, 2018, 46(5): 130-137, 172. 